\title{
Post-partum follow-up of women with gestational diabetes mellitus: Effectiveness, determinants, and barriers
}

Saleha Aziz

Aga Khan University

Tazeen Fatima Munim

Abassi Shaheed Hospital , Karachi , Pakistan

Syeda Sadia Fatima

Aga Khan University, sadia.fatima@aku.edu

Follow this and additional works at: https://ecommons.aku.edu/pakistan_fhs_mc_mc

Part of the Life Sciences Commons

\section{Recommended Citation}

Aziz, S., Munim, T. F., Fatima, S. S. (2018). Post-partum follow-up of women with gestational diabetes mellitus: Effectiveness, determinants, and barriers. Journal of Maternal-Fetal and Neonatal Medicine, 31(12), 1607-1612.

Available at: https://ecommons.aku.edu/pakistan_fhs_mc_mc/127 


\section{PROOF COVER SHEET}

Author(s): Saleha Aziz, Tazeen Fatima Munim, and Syeda Sadia Fatima

Article title: Post-partum follow-up of women with gestational diabetes mellitus: effectiveness, determinants, and barriers

Article no: IJMF_A_1321630

Enclosures: 1) Query sheet

2) Article proofs

Dear Author,

1. Please check these proofs carefully. It is the responsibility of the corresponding author to check these and approve or amend them. A second proof is not normally provided. Taylor \& Francis cannot be held responsible for uncorrected errors, even if introduced during the production process. Once your corrections have been added to the article, it will be considered ready for publication.

Please limit changes at this stage to the correction of errors. You should not make trivial changes, improve prose style, add new material, or delete existing material at this stage. You may be charged if your corrections are excessive (we would not expect corrections to exceed 30 changes).

For detailed guidance on how to check your proofs, please paste this address into a new browser window: http://journalauthors.tandf.co.uk/production/checkingproofs.asp

Your PDF proof file has been enabled so that you can comment on the proof directly using Adobe Acrobat. If you wish to do this, please save the file to your hard disk first. For further information on marking corrections using Acrobat, please paste this address into a new browser window: http://journalauthors.tandf.co.uk/production/ acrobat.asp

2. Please review the table of contributors below and confirm that the first and last names are structured correctly and that the authors are listed in the correct order of contribution. This check is to ensure that your name will appear correctly online and when the article is indexed.

\begin{tabular}{|c|c|c|c|c|}
\hline Sequence & Prefix & Given name(s) & Surname & Suffix \\
\hline 1 & & Saleha & Aziz & \\
\hline 2 & & Tazeen Fatima & Munim & \\
\hline 3 & & Syeda Sadia & Fatima & \\
\hline
\end{tabular}

Queries are marked in the margins of the proofs, and you can also click the hyperlinks below.

\section{General points:}

1. Permissions: You have warranted that you have secured the necessary written permission from the appropriate copyright owner for the reproduction of any text, illustration, or other material in your article. Please see http:// journalauthors.tandf.co.uk/permissions/usingThirdPartyMaterial.asp.

2. Third-party content: If there is third-party content in your article, please check that the rightsholder details for re-use are shown correctly. 
3. Affiliation: The corresponding author is responsible for ensuring that address and email details are correct for all the co-authors. Affiliations given in the article should be the affiliation at the time the research was conducted. Please see http://journalauthors.tandf.co.uk/preparation/writing.asp.

4. Funding: Was your research for this article funded by a funding agency? If so, please insert 'This work was supported by <insert the name of the funding agency in full>', followed by the grant number in square brackets '[grant number xxxx]'.

5. Supplemental data and underlying research materials: Do you wish to include the location of the underlying research materials (e.g. data, samples or models) for your article? If so, please insert this sentence before the reference section: 'The underlying research materials for this article can be accessed at $<$ full link $>/$ description of location [author to complete]'. If your article includes supplemental data, the link will also be provided in this paragraph. See $<\mathrm{http}$ //journalauthors.tandf.co.uk/preparation/multimedia.asp $>$ for further explanation of supplemental data and underlying research materials.

6. The PubMed (http://www.ncbi.nlm.nih.gov/pubmed) and CrossRef databases (www.crossref.org/) have been used to validate the references. Changes resulting from mismatches are tracked in red font.

\section{AUTHOR QUERIES}

Q1: $\quad$ Figures 2A and 2B have been set as Figures 2 and 3, respectively. Please check.

Q2: $\quad$ Please provide the missing volume number and page range for the reference [2] in the references list entry.

Q3: $\quad$ Please provide the missing page range for the reference [6] in the references list entry.

Q4: $\quad$ Please provide the missing volume number and page range for the reference [8] in the references list entry.

Q5: Please provide the missing page range for the reference [15] in the references list entry.

Q6: $\quad$ Please provide the missing page range and volume number for the reference [17] in the references list entry.

Q7: $\quad$ Please provide the missing page range for the reference [21] in the references list entry.

Q8: $\quad$ Please provide the missing page range for the reference [24] in the references list entry.

Q9: $\quad$ Please provide the missing page range for the reference [28] in the references list entry.

Q10: Table 2 was not cited in the text so a citation has been inserted. Please provide a correction if this is inaccurate.

Q11: The ORCID details of the authors have been validated against ORCID registry. please check the ORCID ID details of the authors.

\section{How to make corrections to your proofs using Adobe Acrobat/Reader}

Taylor \& Francis offers you a choice of options to help you make corrections to your proofs. Your PDF proof file has been enabled so that you can mark up the proof directly using Adobe Acrobat/Reader. This is the simplest and best way for you to ensure that your corrections will be incorporated. If you wish to do this, please follow these instructions:

1. Save the file to your hard disk.

2. Check which version of Adobe Acrobat/Reader you have on your computer. You can do this by clicking on the Help" tab, and then About".

If Adobe Reader is not installed, you can get the latest version free from http://get.adobe.com/reader/.

3. If you have Adobe Acrobat/Reader 10 or a later version, click on the Comment" link at the right-hand side to view the Comments pane. 
4. You can then select any text and mark it up for deletion or replacement, or insert new text as needed. Please note that these will clearly be displayed in the Comments pane and secondary annotation is not needed to draw attention to your corrections. If you need to include new sections of text, it is also possible to add a comment to the proofs. To do this, use the Sticky Note tool in the task bar. Please also see our FAQs here: http://journalauthors.tandf.co. uk/production/index.asp.

5. Make sure that you save the file when you close the document before uploading it to CATS using the Upload File" button on the online correction form. If you have more than one file, please zip them together and then upload the zip file. If you prefer, you can make your corrections using the CATS online correction form.

\section{Troubleshooting}

Acrobat help: http://helpx.adobe.com/acrobat.html

Reader help: http://helpx.adobe.com/reader.html

Please note that full user guides for earlier versions of these programs are available from the Adobe Help pages by clicking on the link Previous versions" under the Help and tutorials" heading from the relevant link above. Commenting functionality is available from Adobe Reader 8.0 onwards and from Adobe Acrobat 7.0 onwards.

Firefox users: Firefox's inbuilt PDF Viewer is set to the default; please see the following for instructions on how to use this and download the PDF to your hard drive: http://support.mozilla.org/en-US/kb/view-pdf-files-firefox-without-downloading-them $\#$ w_using-a-pdf-reader-plugin 


\title{
Post-partum follow-up of women with gestational diabetes mellitus: effectiveness, determinants, and barriers
}

\author{
Saleha Aziz ${ }^{\mathrm{a}}$, Tazeen Fatima Munim ${ }^{\mathrm{b}}$ and Syeda Sadia Fatima ${ }^{\mathrm{c}}$ \\ ${ }^{\mathrm{a}}$ Medical College, Aga Khan University, Karachi, Pakistan; ${ }^{\mathrm{b}}$ Department of Obstetrics and Gynecology, Abassi Shaheed Hospital, \\ Karachi, Pakistan; 'Department of Biological and Biomedical Sciences, Aga Khan University, Karachi, Pakistan
}

\section{ABSTRACT}

Background: Despite the recommendations for postpartum blood glucose monitoring post gestational diabetes mellitus (GDM); scientific evidence reveals that these recommendations may not be fully complied to. This study aimed to follow-up women up to 2 years post-delivery with pregnancies complicated by GDM and healthy controls to assess this fact.

Methods: Women with GDM $(n=78)$ and normal glucose tolerant $(n=89)$ delivered in 2014 were followed up for 2 years. They were informed and enquired via telephone about their blood glucose screening, physical activity, postpartum complications, and current weight status of mother and baby.

Results: Women with previous GDM were older and reported higher body weight 2 years postdelivery. At the 2 year follow-up, $n=11$ (14.1\%) participants had developed diabetes, all with previous GDM. Both weight at birth $(3.8 \pm 0.5 \mathrm{~kg})$ and at 2 -year $(10.7 \pm 2.3 \mathrm{~kg})$ for the babies born to GDM mothers was significantly higher than the NGT group babies $(2.6 \pm 0.63$ and $7.1 \pm 1.4 \mathrm{~kg}$; $p<.05)$. Only 27 women regularly opted for T2DM screening via monitoring blood glucose or $\mathrm{HbA1c}$ levels postpartum. The top reason for failed screening included: believing that GDM would disappear after delivery, and being occupied with the baby.

Conclusions: The high incidence of T2DM in women with previous GDM is an alarming finding. Given this trend, systematic follow-up programs are needed to reduce obesity and diabetes risk.
ARTICLE HISTORY

Received 24 February 2017 Accepted 18 April 2017

\section{KEYWORDS}

Gestational Diabetes Mellitus; screening; diabetes mellitus; maternal-fetal outcomes

\section{Introduction}

Glucose levels are regulated and controlled within set limits that are physiologically ideal for the body to perform all functions. For most healthy individuals, blood glucose levels are tightly controlled between fasting and fed state [1]. Any derangement in these levels may lead to development of diabetes in an individual. One such form of diabetes seen during pregnancy (irrespective of whether the condition prolongs post-partum or not) is commonly referred to as Gestational diabetes (GDM). GDM is widespread around the world, however, the prevalence depends on the country, region within the country, socio-economic status, and dietary habits of an individual, and the criteria used for diagnosis [2]. One in 250 pregnant women in the United Kingdom are diabetic, majority of these cases (87.5\%) have GDM [3]. In a recent study conducted by our group, a GDM prevalence of $17 \%$ for women visiting tertiary care hospitals in Karachi was reported [4], which is comparable to Western statistics [5]. However, reports have shown that the complication rates are far greater, plausibly due to poor glycemic control in our population [6].

Like other forms of diabetes, gestational diabetes can affect glucose usage by cells which can have repercussions on maternal, fetal, and neonatal health and presently GDM can be used as a predictive indicator of morbidity in index pregnancies [7]. Several trials and studies have shown that it is associated with multiple fetal and maternal complications, some of which are shown in schematic Figures 1 and $z_{1}$ [8]. Even though serious perinatal complications which are specifically related to GDM are uncommon, macrosomia is known to be the predominant complication in cases of GDM. Moreover, the neonate is also at risk of developing several problems shown in Figure 3 [9]. In order to prevent these, early screening and strict blood glucose control is recommended in GDM patients. Apart from the complications listed above, an additional

CONTACT Syeda Sadia Fatima sadia.fatima@aku.edu D Department of Biological and Biomedical Sciences, Aga Khan University, Stadium Road, Karachi-74800, Pakistan

(C) 2017 Informa UK Limited, trading as Taylor \& Francis Group 
(A)

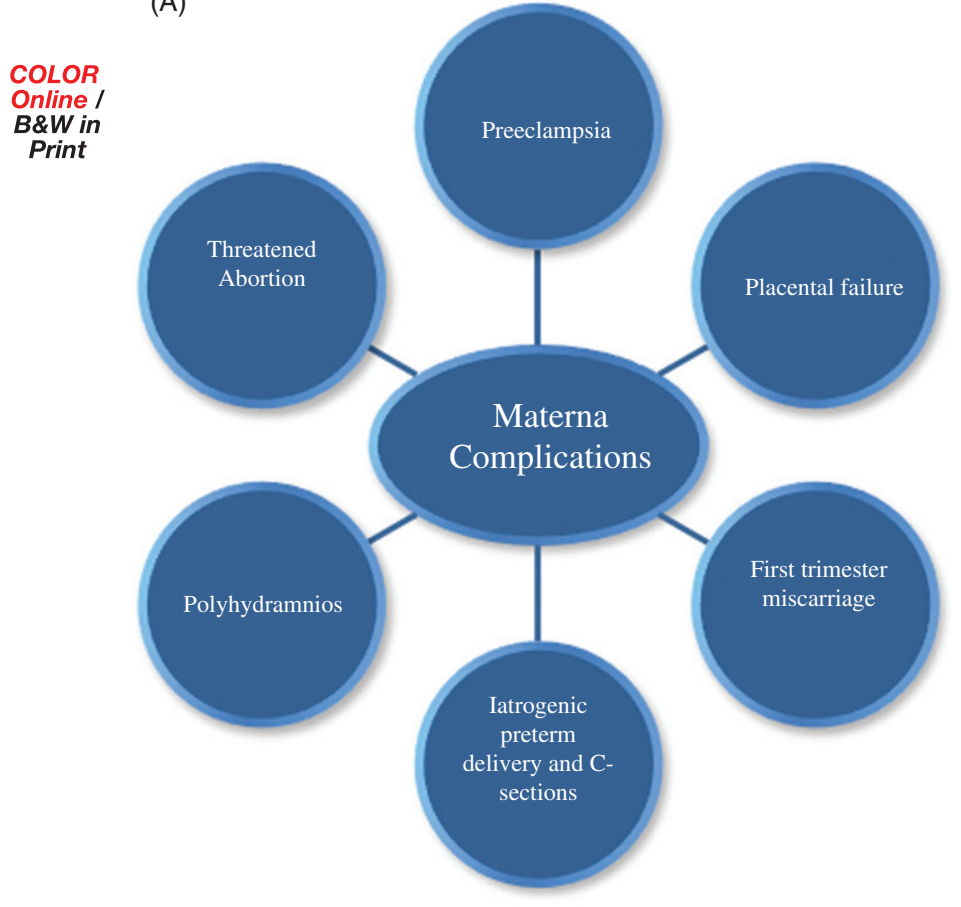

(B)

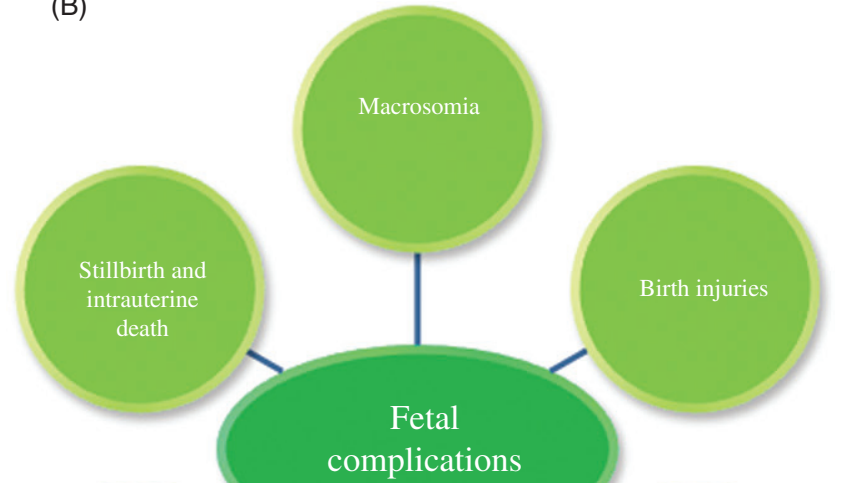

(C)

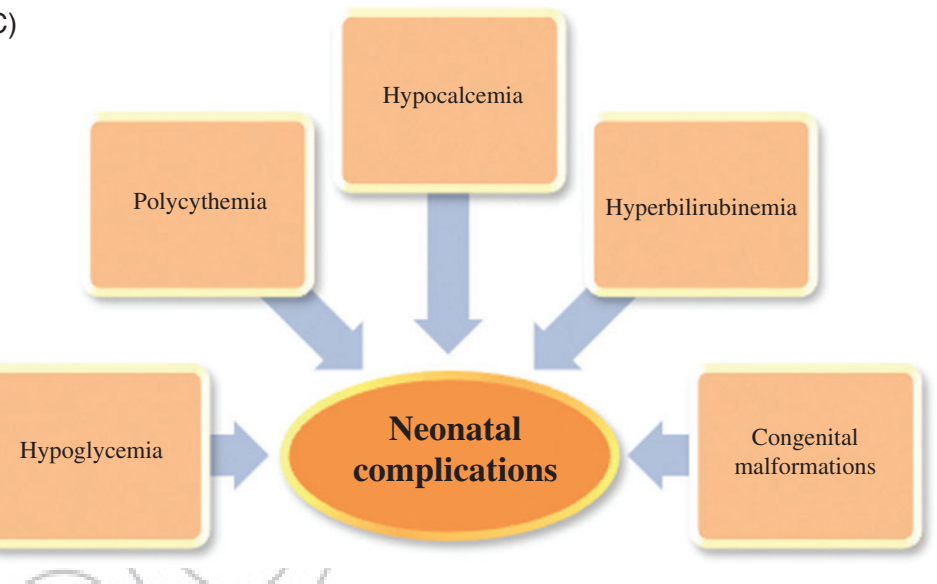

Figure 1. (A-C) Sumarizes the maternal, fetal, and neonatal complications.

burden on these females is due to the fact that a previous diagnosis of GDM results in a lifetime risk of development to Type 2 diabetes mellitus (T2DM) [10]. Though there are no guarantees when they will develop T2DM postpartum, however, some precautionary measure can reduce the risk of developing it. These include maintaining high fiber and low fat diet, regular exercise, and losing excess weight before pregnancy and the most important factor regular blood glucose screening $[11,12]$. Though, all these facts are well-known but a vast majority of GDM females do not follow them. Therefore, we aimed to conduct a follow up study to identify how many GDM positive females followed the blood glucose screening instructions and developed any complications during or after pregnancy at tertiary care hospitals in Karachi, Pakistan.

\section{Materials and methods}

This follow-up study included women with and without GDM with uncomplicated pregnancies delivered in the year 2014. These women were recruited for the antenatal care clinics of Abassi Shaheed Hospital, Karachi. Over 500 pregnant females, less the 20 weeks' gestation were identified as possible candidates for the study. Out of the potential subjects, 179 females (35.8\%) consented to participate in the follow-up study. Eventually, we lost 12 more subjects due to concurrent pregnancies or failure to respond. The final sample at the completion of this study was $n=167$ and this was considered appropriate to achieve a power of $80 \%$ with an alpha of 5\% [13]. Subjects with a pre-pregnancy history of diabetes, hypertension, conception due to assisted reproductive techniques 


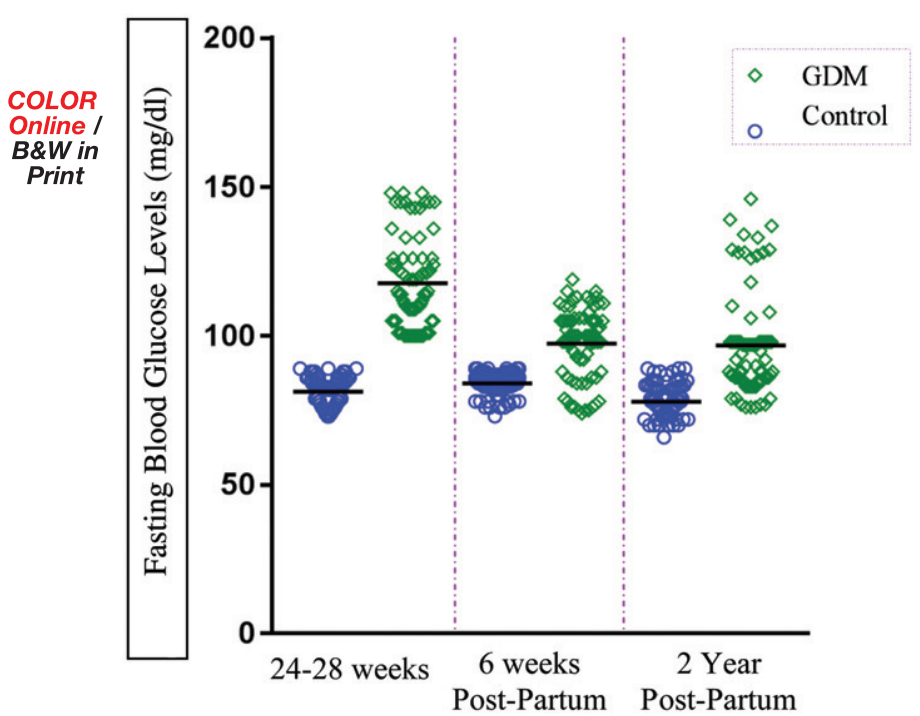

Figure 2. Periodic fasting blood glucose levels of the study subjects. The FBG levels at 24-28 weeks for NGT and GDM were77.95 $\pm 5.39 \mathrm{mg} / \mathrm{dl} ; 96.83 \pm 17.27 \mathrm{mg} / \mathrm{dl}$; at 6 weeks postpartum was $81.18 \pm 4.77 \mathrm{mg} / \mathrm{dl} ; 117.71 \pm 15.05 \mathrm{mg} / \mathrm{dl}$ and at 2 year postpartum was $84.01 \pm 3.64 \mathrm{mg} / \mathrm{dl}$ and GDM was $97.42 \pm 11.70 \mathrm{mg} / \mathrm{dl}$, respectively.

,
Developed T2DM

Pre-Diabetic FBG 100 to $125 \mathrm{mg} / \mathrm{dl}$

Figure 3. Screening and incidence of T2DM in GDM positive females.

and any other maternal-fetal health issues were excluded from this study. A $75 \mathrm{~g}$ oral glucose test was used to diagnose GDM and normal glucose tolerance (NGT) in study subjects. The GDM diagnostic criteria and the desired glucose levels used as a reference in this study are shown in Table 1. A total of 78 GDM positive women and 89 healthy controls were followed up from the time of delivery till 2 year postpartum. GDM women were managed by either medical nutrition therapy $(n=32)$ or medicine (insulin $n=35$ and metformin $n=11$ ). Periodic records were made as follows: (i) antenatal data included pre-pregnancy weight, body mass index (BMI), family history of diabetes, fasting blood glucose (FBG), HbA1c, fetal growth scans,

Table 1. Diagnostic criteria and glycemic targets for GDM.

International Association of Diabetes and Pregnancy Study Group (IADPSG) Criteria for GDM diagnosis [1]

GDM is diagnosed when any of the following reading is observed:

Fasting blood glucose (FPG): $\geq 92 \mathrm{mg} / \mathrm{dL}(5.1 \mathrm{mmol} / \mathrm{L})$

1-h blood glucose: $\geq 180 \mathrm{mg} / \mathrm{dL}(10.0 \mathrm{mmol} / \mathrm{L})$

2-h blood glucose: $\geq 153 \mathrm{mg} / \mathrm{dL}(8.5 \mathrm{mmol} / \mathrm{L})$

Recommendation for post-partum screening

Women with a history of GDM should have lifelong screening for the development of diabetes or pre-diabetes at least every 3 years

Women with a history of GDM found to have pre-diabetes should receive lifestyle interventions or metformin to prevent diabetes

Diabetes is diagnosed when any of the following is observed

HbA1C: $>6.5 \%$

FBG: $\geq 126 \mathrm{mg} / \mathrm{dL}(7.0 \mathrm{mmol} / \mathrm{L})$

2-h blood glucose: $>200 \mathrm{mg} / \mathrm{dL}(11.1 \mathrm{mmol} / \mathrm{L})$ during an OGTT

A random plasma glucose: $\geq 200 \mathrm{mg} / \mathrm{dL}(11.1 \mathrm{mmol} / \mathrm{L})$

and baby birth weight (ii) at delivery data included maternal and baby birth weight, APGAR score (iii) at 6 weeks postpartum data included screening by GTT/ $\mathrm{HbA} 1 \mathrm{c}$, weight status of mother and baby and maternal FBG were recorded. From this point forward all study subjects received reminders for lifestyle modification as well as blood glucose screening via telephone at 6 month, 12 month, and 24 month postpartum. An independent researcher interviewed all females and recorded their answers on a prescribed form. After 2 years these females were examined with their babies and at that point the weight status and FBG of the mother and the weight and vaccination status of the baby were recorded. The WHO growth chart guidelines were used to assess the age for weight as follows: (A) weight at birth for boys $3.0-3.7 \mathrm{~kg}(6.7-8.1 \mathrm{lbs}$.$) and girls 2.9-3.5 \mathrm{~kg}(6.5-7.8$ lbs.) and (B) weight at 24 months for boys $11.2-13.1 \mathrm{~kg}$ (24.8-28.9 lbs.) and girls $10.5-12.4 \mathrm{~kg}$ (23.3-27.5 lbs.) [14]. The study was approved by the institutional ethical committee (Table 2

Data were analyzed Mean \pm SD while qualitative data was presented as absolute number with percentage in parenthesis. Student $t$ test, Pearson chi-square test/Fisher exact test were used to compare groups. In all instances $p$ values $<.05$ was considered as significant.

\section{Results}

The details of the result are shown in Fable The mean age of study subjects with GDM as $28.94 \pm 2.84$ year while for control was $25.68 \pm 3.01$ year. Women with previous GDM had higher body weight before pregnancy and postpartum compared to the control group $(p<.05)$. Interestingly, no difference was observed in both groups in terms of being physically active. Cesarian section deliveries were common in 
Table 2. Details of study subjects.

\begin{tabular}{|c|c|c|}
\hline Variable & GDM $n=78$ & NGT $n=89$ \\
\hline \multicolumn{3}{|l|}{ Antenatal data } \\
\hline Maternal age (year) & $28.94 \pm 2.84^{*}$ & $25.68 \pm 3.01$ \\
\hline Maternal weight (<20 weeks gestation) (kg) & $69.5 \pm 8.22^{* *}$ & $56.54 \pm 5.42$ \\
\hline \multicolumn{3}{|l|}{ Parity } \\
\hline Primi-parous & $63(80 \%)$ & $76(85 \%)$ \\
\hline Multi-parous & $15(20 \%)$ & $13(15 \%)$ \\
\hline \multicolumn{3}{|l|}{ Intrauterine fetal growth scan } \\
\hline Normal for gestational age & $26(33.3)$ & $62(69.6)^{*}$ \\
\hline Large for gestational age & $47(60.0)^{*}$ & $17(19.1)$ \\
\hline Small for gestational age & $5(6.4)$ & $10(11.2)^{*}$ \\
\hline \multicolumn{3}{|l|}{ Delivery data } \\
\hline Normal vaginal delivery & $38(48.7)$ & $56(62.2)^{*}$ \\
\hline Cesarian section delivery & $40(51.2)^{*}$ & $33(37.7)$ \\
\hline Baby weight at birth (reference range $2.4-4.2 \mathrm{~kg}$ ) & $4.5 \pm 0.5^{*}$ & $3.6 \pm 0.6$ \\
\hline \multicolumn{3}{|l|}{ Follow-up data } \\
\hline Maternal weight at 6 weeks post-partum (kg) & $73.26 \pm 6.86^{* *}$ & $67.23 \pm 4.65$ \\
\hline Maternal weight at 2 year postpartum $(\mathrm{kg})$ & $78.65 \pm 12.32^{* *}$ & $65.22 \pm 4.23$ \\
\hline Sedentary life style & $69(88.4)$ & $74(83.1)$ \\
\hline 30 min walk three times a week & 09 (11.5) & $15(16.8)$ \\
\hline Baby weight at 2 year (reference range $9.5-14.5 \mathrm{~kg}$ ) & $14.9 \pm 2.3^{*}$ & \\
\hline
\end{tabular}

GDM group (51\%) versus control group (37\%), mostly due to large for gestational age fetus. Both weight at birth $(4.5 \pm 0.5 \mathrm{~kg})$ and at 2-year $(14.9 \pm 2.3)$ for the babies born to GDM mothers was significantly higher than the control group babies $(3.6 \pm 0.6$ and $10.7 \pm 1.4$; $p<.05$ ). Figure $1(A)$ ows the blood glucose levels at 28th week of ges n, 6 weeks and 2 year post-partum. At all times the FBG for GDM group was higher than the NGT group $(p<.01)$. Furthermore, in terms of screening only 27 women with GDM regularly opted for T2DM screening either by monitoring $\mathrm{HbA1c}$ levels or repeat $75 \mathrm{~g}$ glucose tolerance test postpartum. 11 were diagnosed with diabetes at the time of while three were diagnosed as pre-diabetic follow-up interviey The top reason given for not following screening inst 2 on was that GDM would disappear after delivery, testing will falsely diagnose them as T2DM and being occupied with the baby.

\section{Discussion}

Maternal age, higher than normal BMI, high parity, previous history of gestational diabetes, and family history of diabetes can pose as risks for developing gestational diabetes [15]. Our results showed that the group of women with GDM had higher body weight as opposed to those who did not develop GDM. Obesity is an established risk factor towards the development of both gestational diabetes as well as T2DM [13]. It affects maternal health and may also have significant adverse effects on fetal, neonatal, and longterm health and well-being [16].

The rate of development of T2DM after a pregnancy complicated by gestational diabetes ranges from as low as $2-6 \%$ to as high as $70 \%$ in studies examining women from 6 weeks to 28 year post-partum [17-20]. Compared to women with a history of normo-glycemic pregnancies, those with prior GDM have more than sevenfold increased risk of developing T2DM [21]. Screening for T2DM after pregnancy is, therefore, recommended every 1-3years in this risk group. Intervention strategies can be considered in the case of early detection, especially in women of childbearing age resulting in better prognosis [22]. To add to this burden South Asians are prone to develop diabetes after GDM at a higher rate and at an earlier stage. Despite this fact, many women do not follow the instructions of health care providers and as a result a golden opportunity of early detection is missed in most cases.

In the present study, we sent periodic telephonic reminders to our study participants for blood glucose screening. Despite all the vigilance, only a limited number of participants $(n=27)$ opted for the screening either by $75 \mathrm{~g}$ OGTT or by HbA1c level. We report an alarming incidence $14 \%(n=11)$ of T2DM in females with a past medical history of gestational diabetes, and 3.8\% $(n=3)$ diagnosed as impaired glucose tolerant. At the 5-year follow-up study from India reported the conversion rate to T2DM up to $37 \%$ in women with previous GDM [23]. Furthermore, low rates of attendance at the 6-week follow-up suggest that perhaps women with gestational diabetes do not properly acknowledge the significance of this disorder as an early warning sign of the susceptibility to develop T2DM later in life. This behavior identifies the need for enhancing awareness for both health care providers as well as women with previous GDM, which 
results in missed opportunities in early identification and diagnosis.

When we asked the remaining females why they did not opt for screening despite receiving constant reminders, the top reasons for failed screening included believing that GDM would disappear after delivery, since this is commonly referred to as baby sugar; they were too occupied with the baby and if they repeated the test, it will falsely label them as diabetic. The lack of compliance for T2DM screening might be attributed to factors such as fear of insulin use and long periods of post-partum follow-up [24]. Various other barriers preventing the timely screening such as "challenges in testing women in the fasting state, need for repeated testing, screening procedure being too time consuming, scarcity of test consumables and lack of equipment" are also contributing factors for the low screening rate [25]. Yet, by utilizing e-health component in generating awareness and periodic reminders during the course of this study, we were successful in stimulating $34.6 \%(n=27)$ of our GDM women to get themselves screened. The effectiveness of sending periodic reminders in improving the compliance for testing is also reported by studies from developed countries such as Canada, Australia, and USA [26-29].

In addition to the above follow-up findings, we also collected antenatal and at delivery data of the newborn. We observed that babies of GDM positive mothers both during intrauterine scans and at delivery had a higher body weight. This factor was a major contributor to the high rate of cesarean section in this group. This trend progressed for these babies and at 2 year post-partum; they were at a higher weight for age percentile when compared with babies born to NGT females. Previous literature supports a positive correlation between maternal blood glucose levels, increased birth weight, and neonatal adiposity [8], therefore our findings were consistent with them. This relationship is probably due to fetal hyper-insulinism, which is secondary to maternal hyperglycemia, and maternal obesity can act as an additional risk factor to develop macrosomia.

Like all studies, there are some limitations and strengths. First, we were unable to recruit a larger number of subjects, and second only limited number of recruits was complaint with screening protocol. Third, screening bias is a concern when there is a potential for more health-conscious women to regularly see a physician, thus increasing their chance of receiving a medical diagnosis. Yet, there are various strengths as to being a follow-up study in Pakistan where there is scarcity of follow up-based research.
Moreover, based on the Pakistani population, the homogeneity of this study advantageously reduces potential sources of unmeasured confounding. Future research will result in greater advances in this field. This study also allows for recommendations to be formed and implemented, which will work towards better pregnancy care. Further, we have established that there is a dire need to spread awareness of the complications of GDM, encouraging mothers to followup on their glucose levels even after pregnancy. Additionally, physical activity should be advised to reduce the burden of disease in GDM patients.

\section{Conclusions}

Lack of awareness for follow-up screening in GDM positive women is high in our region. The incidence of developing T2DM in 14\% women with previous GDM in a short-term follow up study is an alarming finding. Given this trend, systematic follow-up programs and awareness of both physicians and pregnant women are needed to reduce obesity and diabetes risk.

\section{Ethical approval}

All procedures performed in this study involving human participants were in accordance with the ethical standards of the institutional research committee and with the 1964 Helsinki declaration and its later amendments or comparable ethical standards.

\section{Acknowledgements}

The authors wish to thank all study participates for this study.

\section{Disclosure statement}

The authors declare that they have nothing to disclose.

\section{Funding}

This research did not receive any specific grant from funding agencies in the public, commercial, or not-for-profit sectors.

\section{ORCID}

Syeda Sadia Fatima (D) http://orcid.org/0000-0002-3164-0225

\section{References}

[1] Panel IC. International association of diabetes and pregnancy study groups recommendations on the 
diagnosis and classification of hyperglycemia in pregnancy. Diabetes Care. 2010;33:676-682.

[2] Rajesh Rajput YY, Nanda S, Rajput M. Prevalence of gestational diabetes mellitus \& associated risk factors at a tertiary care hospital in Haryana. Indian J Med Res. 2013.

[3] Narayanan RP, Samad S. Improving outcomes in diabetes in pregnancy. Practitioner. 2015;259:25-28, 3.

[4] Fatima SS, Rehman R, Alam F, et al. Gestational diabetes mellitus and the predisposing factors. JPMA. 2017;22:98.

[5] Wild S, Roglic G, Green A, et al. Global prevalence of diabetes: estimates for the year 2000 and projections for 2030. Diabetes Care. 2004;27:1047-1053.

[6] Syed W. Obesity related maternal complications in pregnant women. Khyber Med Univ J. 2014; $\sigma_{2}$

[7] Russell C, Dodds L, Armson B, et al. Diabetes mellitus following gestational diabetes: role of subsequent pregnancy. BJOG. 2008;115:253-260.

[8] Hartling L, Dryden DM, Guthrie A, et al. Screening and diagnosing gestational diabetes mellitus. Evid Rep Technol Assess (Full Rep). 2012;1-327.

[9] Fazel-Sarjoui Z, Khodayari Namin A, Kamali M, et al. Complications in neonates of mothers with gestational diabetes mellitus receiving insulin therapy versus dietary regimen. Int J Reprod BioMed. 2016;14:275-278.

[10] Hakkarainen $\mathrm{H}$, Huopio $\mathrm{H}$, Cederberg $\mathrm{H}$, et al. The risk of metabolic syndrome in women with previous GDM in a long-term follow-up. Gynecol Endocrinol. 2016;32: 920-925.

[11] Riaz M, Basit A. Integrating GDM management in public health: Pakistan perspective. J Pak Med Assoc. 2016;66:S101

[12] Schmidt MI, Duncan BB, Castilhos C, et al. Lifestyle INtervention for Diabetes prevention After pregnancy (LINDA-Brasil): study protocol for a multicenter randomized controlled trial. BMC Pregnancy Childbirth. 2016;16:1.

[13] Nathan DM. Diabetes: advances in diagnosis and treatment. JAMA. 2015;314:1052-1062.

[14] Grummer-Strawn LM, Reinold CM, Krebs NF, et al. Prevention. Use of World Health Organization and CDC growth charts for children aged 0-59 months in the United States. Department of Health and Human Services, Centers for Disease Control and Prevention; 2010.

[15] Khan A RK, Khan Z. Socio-demographic risk factors of Gestational Diabetes Mellitus. Pak J Med Sci. 2013;29.

[16] Vasudevan C, Renfrew M, McGuire W. Fetal and perinatal consequences of maternal obesity. Arch Dis Child Fetal Neonatal Ed. 2011;96:F378-F382.
[17] McGrath R, Hocking S, Scott E, et al. Outcomes of twin pregnancies complicated by gestational diabetes: a meta-analysis of observational studies. J Perinatol. 2017.

[18] Moon JH, Kwak SH, Jang HC. Prevention of type 2 diabetes mellitus in women with previous gestational diabetes mellitus. Korean J Intern Med. 2017;32:26.

[19] Barry E, Roberts S, Oke J, et al. Efficacy and effectiveness of screen and treat policies in prevention of type 2 diabetes: systematic review and meta-analysis of screening tests and interventions. BMJ. 2017;356:i6538

[20] Kim C, Newton KM, Knopp RH. Gestational diabetes and the incidence of type 2 diabetes: a systematic review. Diabetes Care. 2002;25:1862-1868.

[21] Tobias DK, Hu FB, Chavarro J, et al. Healthful dietary patterns and type 2 diabetes risk among women with a history of gestational diabetes. Arch Intern Med. 2012;172.

[22] Brink HS, Alkemade $M$, van der Lely AJ, et al Investigating screening for diabetes in women with a history of gestational diabetes. Neth J Med. 2016;74: 429-433.

[23] Krishnaveni GV, Hill JC, Veena SR, et al. Gestational diabetes and the incidence of diabetes in the 5 years following the index pregnancy in South Indian women. Diabetes Res Clin Pract. 2007;78:398-404.

[24] Bentley-Lewisa R. Gestational diabetes mellitus: an opportunity of a lifetime. Lancet. 2009;373:

[25] Nielsen KK, Courten M, Kapur A. The urgent need for universally applicable simple screening procedures and diagnostic criteria for gestational diabetes mellitus-lessons from projects funded by the World Diabetes Foundation. Glob Health Action. 2012;5: 17277.

[26] Morrison MK, Collins CE, Lowe JM. Postnatal testing for diabetes in Australian women following gestational diabetes mellitus. Australian. Aust N Z J Obstet Gynaecol. 2009;49:494-498.

[27] Clark HD, Graham ID, Karovitch A, et al. Do postal reminders increase postpartum screening of diabetes mellitus in women with gestational diabetes mellitus? A randomized controlled trial. Am J Obstetr Gynecol. 2009;200:634. e1-6e7.

[28] Shea A, Sha B, Clark $H$, et al. The effectiveness of implementing a reminder system into routine clinical practice: does it increase postpartum screening in women with gestational diabetes? Chronic Dis Inj Can. 2011;31.

[29] Kim C, McEwen LN, Kerr EA, et al. Preventive counseling among women with histories of gestational diabetes mellitus. Diabetes Care. 2007;30:2489-2495. 